\title{
Effects of Panax notoginseng flower extract on the TGF- $\beta$ /Smad signal transduction pathway in heart remodeling of human chymase transgenic mice
}

\author{
YOUHUA WANG ${ }^{1,2}$, PEIGANG QIAN ${ }^{3,4}$, PING LIU $^{1}$, LI WEI $^{5}$, \\ MIN CAO $^{1}$, LI ZHOU ${ }^{1}$, DUAN ZHOU ${ }^{1}$ and ZHI-XIU LIN ${ }^{2}$ \\ ${ }^{1}$ Longhua Hospital, Shanghai University of Traditional Chinese Medicine, Shanghai 200032; \\ ${ }^{2}$ School of Chinese Medicine, Faculty of Science, The Chinese University of Hong Kong, \\ Shatin, N.T., Hong Kong SAR; ${ }^{3}$ Department of Pharmacology, College of Pharmaceutical Science, Soochow University, \\ Suzhou 215123; ${ }^{4}$ Suzhou Institute of Chinese Materia Medica, School of Pharmacy, \\ Medical College of Soochow University, Suzhou 215123; ${ }^{5}$ School of Chinese Materia Medica, \\ Shanghai University of Traditional Chinese Medicine, Shanghai 201203, P.R. China
}

Received September 11, 2011; Accepted December 8, 2011

DOI: $10.3892 / \mathrm{mmr} .2012 .856$

\begin{abstract}
Panax notoginseng is a common Chinese herb extensively used in Chinese medical practice for the treatment of cardiovascular diseases. The present study aimed to evaluate the effects of Panax notoginseng flower extract (PNFE) on the TGF- $\beta$ /Smad signal transduction pathway in heart remodeling of human chymase transgenic mice. After treatment with PNFE and soybean trypsin inhibitor (SBTI), the left ventricular mass indexes (LVMIs) of transgenic and normal C57 BL/6 mice were analyzed. The mRNA expression of chymase, TGF- $\beta 1$, Smad2, Smad3 and Smad7 in myocardium was assessed with RT-PCR, while the protein expression in myocardium was detected by western blotting. The results showed that PNFE and SBTI treatment led to a significant reduction in LVMIs in transgenic mice, indicating a beneficial effect on left ventricular remodeling. Mechanistically, PNFE and SBTI treatment attenuated the mRNA expression of chymase, TGF- $\beta 1$, Smad 2 and Smad3, as well as the protein expression in the myocardium tissues of the transgenic mouse model. By contrast, PNFE and SBTI treatment markedly up-regulated the mRNA and protein expression of Smad7. It was concluded that PNFE was able to improve the ventricular
\end{abstract}

Correspondence to: Professor Duan Zhou, Longhua Hospital, Shanghai University of Traditional Chinese Medicine, Shanghai 200032, P.R. China

E-mail: zhouduan@126.com

Dr Zhi-Xiu Lin, School of Chinese Medicine, Faculty of Science, The Chinese University of Hong Kong, Shatin, N.T., Hong Kong SAR, R.O.C.

E-mail:linzx@cuhk.edu.hk

Key words: Panax notoginseng flower, TGF- $\beta /$ Smads, heart remodeling, human chymase transgenic mice hypertrophy state in human chymase transgenic mice through regulation of the expression of mRNA and protein of TGF- $\beta$ / Smad in ventricular tissues.

\section{Introduction}

Heart remodeling in the form of left ventricular hypertrophy $(\mathrm{LVH})$ is very common during hypertension and is considered as the first step towards myocardial infarction or heart failure (1). Evidence that a large variety of genes and pathways are involved in the alterations of cardiac growth in animal models, such as transgenic mice, and in patients, supports the concept of genetic susceptibility in LVH (2-4). Chymase is one of the angiotensin II (Ang II)-producing enzymes and is a chymotrypsin-like serine protease found in abundance in the secretory granules of mast cells (5). In patients with heart failure, the cardiac mast cell density is markedly increased, and an increased level of chymase may play a role in the development of several cardiovascular diseases (6,7). Several studies have indicated a close association of chymase in the development of heart remodeling (8-12). Chymase inhibitors, such as soybean trypsin inhibitor (SBTI), also a proteinase inhibitor on tryptase, have been found to be highly effective in mitigating tryptase and chymase-induced damage in cardiac tissues $(9,13,14)$.

Transforming growth factor- $\beta$ (TGF- $\beta$ ) has been reported to be crucial in the progression of LV remodeling (15), a pathophysiological process characterized by hypertrophy of cardiomyocytes and an increase in interstitial fibrosis. Cardiac chymase promotes fibrosis by activating the production of TGF- $\beta(9,16)$, and also enhances Ang II production (17). Moreover, chymase also induces cardiac profibrotic response via TGF- $\beta 1 /$ Smad signaling activation $(18,19)$. However, the involvement of TGF- $\beta 1 /$ Smad signaling activation in heart remodeling has yet to be reported in any chymase gene transgenic study. 
Panax notoginseng (Burk) F.H. Chen has long been used in Chinese medicine for the treatment of a wide array of diseases. Modern pharmacological research has found that Panax notoginseng exerts a variety of pharmacological effects on the blood, cardio-cerebral vascular system, central nervous system and endocrine system (20). Although the roots of this plant are the most commonly used, other plant parts, such as the rootlets, leaves and flowers, are also used, and their therapeutic activities and safety profiles are found to be similar to that of the roots (21).

Panax notoginseng saponins (PNS), the principal ingredients extracted from Panax notoginseng, have extensive effects on the cardiovascular system, including, among others, inhibition of platelet aggregation, invigorating blood flow in the coronary arteries $(22,23)$, improving left ventricular diastolic function in hypertensive patients (23), protecting against damage resulting from myocardial ischemia (24), reducing myocardial oxygen consumption and anti-arrhythmic action (25). However, the effect of the Panax notoginseng flower extract (PNFE) on heart diseases, such as ventricular hypertrophy, has yet to be evaluated. Based on our unpublished screening data, the ventricular hypertrophy attenuating effect of NGFE is stronger than that of the root extract. In this study, we aimed to investigate the effects of PNS derived from the flower buds of Panax notoginseng on ventricular hypertrophy of human chymase transgenic mice, and to elucidate the underlying mechanisms of action by investigating the TGF- $\beta$ / Smads signaling transduction pathway in ventricular tissues.

\section{Materials and methods}

Preparation and determination of PNFE. The flowers of Panax notoginseng used in the present study were collected in the Wenshan region of Yunnan Province, China, in February 2007, and their botanical identity was authenticated at the Yunnan Wenshan Cotrun Center Co., Ltd. To prepare the saponin-rich PNFE, $1 \mathrm{~kg}$ of Panax notoginseng flowers was refluxed with 14 liters $70 \%$ aqueous ethanol three times, for $2 \mathrm{~h}$ each time. The pooled extract was then concentrated to $\sim 0.4 \mathrm{~g} / \mathrm{ml}$ on a rotary evaporator under negative pressure, and the concentrate was then passed through a filter to remove any large debris. The refined concentrate was then loaded onto a AB-8 macroporous resin (Chemical Factory of Nankai University, Tianjin, China) column using an optimized protocol according to a method used by Li et al (26). Briefly, the column was eluted with $70 \%$ aqueous ethanol and the elute was then evaporated to yield dry PNFE. The total saponins in the dry PNFE were then quantified to be $87.6 \%$ using UV spectrophotometer (UV 8453; Agilent Technologies, USA). The amount of ginsenoside $\mathrm{Rb} 1$ and Rb3 was 4.12 and $8.93 \%$, respectively, based on HPLC analysis (1200 series; Agilent Technologies) compared to the ginsenoside $\mathrm{Rb} 1$ and $\mathrm{Rb} 3$ reference sample solutions (National Institute for the Control of Pharmaceutical and Biological Products, China).

Animals. C57 BL/6 mice were obtained from the Institute of Experimental Animals, Chinese Academy of Medical Sciences [Licence No. SCXK (Beijing) 2005-0013]. In some studies, human chymase gene transgenic mice were produced from C57 BL/6 genetic background mice $(8,27)$. In brief, to construct the myosin light chain-2 promoter (MLC2)-chymase fusion gene and produce transgenic mice for overexpression of the chymase gene in mouse heart, the MLC2-chymase fusion gene was constructed by splicing the MLC2 promoter sequence with the cloned chymase structural gene, whose promoter sequence had been deleted by nuclease BAL31 and cloned through molecular cloning. Purified fusion gene fragments were microinjected into murine eggs and transgenic mice were produced. PCR amplification, Southern blot analysis and sequencing of the products of PCR amplification were used to identify the positive transgenic mice.

The animals were housed in a 12-h light/dark cycle room and were allowed free access to food and water. Male human chymase gene transgenic mice ( 7 months of age) were randomly divided into three groups, with 8 animals in each group: i) control group, in which the animals were treated with double distilled water, i.g., once every day; ii) the SBTI group, in which the animals were treated with $20 \mathrm{mg} / \mathrm{kg} /$ day SBTI (Sigma), i.g., once every day according to a protocol previously described by Matsumoto et al (9); and iii) the PNFE-treated group, in which animals were administered $120 \mathrm{mg} / \mathrm{kg} /$ day of PNFE, i.g., once daily. C57 BL/6 mice (7 months of age; $\mathrm{n}=8$ ) were used as a normal untreated group, in which animals were treated with double distilled water, i.g., once every day. Treatments for all groups lasted for 9 consecutive weeks.

Left ventricular mass quantification. At the end of the treatment period, mice were sacrificed by an overdose of pentobarbital sodium. The chests of the mice were cut open, and both the left and right atria and ventricles were dissected and weighed. Left ventricular hypertrophy index (LVHI) was calculated using the following formula: LVHI = ventricle weight/body weight $(\mathrm{mg} / \mathrm{g})$. The myocardial tissues were also used for PCR and western blot analysis.

Reverse transcription (RT)-PCR analysis. Subsequent to left ventricular mass quantification, the left ventricular tissues were stored in dry ice. Total RNA was extracted from $100 \mathrm{mg}$ ventricular tissue using TRIzol reagent (Invitrogen, Carlsbad, CA, USA) according to the manufacturer's instructions. The ventricular tissues were pooled in equal amounts in each group to reduce inter-animal variations. RT-PCR for the detection of the mRNA expression of chymase, TGF- $\beta 1$, Smad2, Smad3 and Smad7 was performed. Reversed transcription to cDNA was synthesized by analyzing $5 \mathrm{mg}$ of the total RNA sample with SuperScript II reverse transcriptase and oligo(dT) primer (Invitrogen). The reaction was carried out in the presence of first-strand buffer, $1 \mathrm{mmol} / \mathrm{l} \mathrm{dNTPs}$ and $20 \mathrm{~mol} / \mathrm{l}$ dithiothreitol. The PCR mixture contained $1 \mathrm{ml}$ of the cDNA reaction mixture, $20 \mathrm{pmol} / 1$ primers, PCR buffer, $0.4 \mathrm{mmol} / \mathrm{l}$ dNTPs and 2.5 units Taq polymerase. The PCR products were separated by electrophoresis on $2 \%$ agarose gel stained with ethidium bromide, and the samples were then visualized by ultraviolet transillumination. The reaction was performed with a RoboCycler (Stratagene, LaJolla, CA, USA). Sequences of the oligonucleotide primers for PCR are shown in Table I.

Western blot analysis. Ventricular tissues (100 mg) were lysed in $0.30 \mathrm{ml}$ lysis buffer consisting of $20 \mathrm{mmol} / 1 \mathrm{Tris} / \mathrm{HCl}$, $\mathrm{pH}$ 7.4, $100 \mathrm{mmol} / \mathrm{l} \mathrm{NaCl}, 10 \mathrm{mmol} / \mathrm{l}$ sodium pyrophosphate, 
Table I. Primers used in the RT-PCR analysis.

\begin{tabular}{llc}
\hline $\begin{array}{l}\text { Primer } \\
\text { pair }\end{array}$ & \multicolumn{1}{c}{$\begin{array}{c}\text { Sequence } \\
\left(5^{\prime}-3^{\prime}\right)\end{array}$} & $\begin{array}{c}\text { Fragment } \\
\text { size (bp) }\end{array}$ \\
\hline$\beta$-actin & CCTCTATGCCAACACAGTGC & 211 \\
Chymase & AGCTCACTGTGCGGGAAGGTCTA & 231 \\
TGF- $\beta 1$ & GCACCGGAGAGCCCTGGATAC & 226 \\
Smad2 & CTCTCCGGCTGAACTGTCTCCTAC & 187 \\
Smad3 & TCCACGCCTCACAGCCATCCAT & 244 \\
Smad7 & CCCGGCGGCGAGGACGAGGAG & 183 \\
\hline
\end{tabular}

$5 \mathrm{mmol} / \mathrm{l} \mathrm{EDTA}, 50 \mathrm{mmol} / \mathrm{l} \mathrm{NaF}, 1 \mathrm{mmol} / \mathrm{l}$ sodium vanadate, $0.1 \%(\mathrm{w} / \mathrm{v})$ sodium dodecyl sulphate (SDS), $10 \%(\mathrm{w} / \mathrm{v})$ glycerol, 1\% (v/v) Triton X-100, 1\% (w/v) sodium deoxycholate, $1 \mu \mathrm{mol} / 1$ leupeptin, $0.1 \mu \mathrm{mol} / 1$ aprotinin, $1 \mu \mathrm{mol} / 1$ phenylmethylsulphonyl fluoride and $1 \mu \mathrm{mol} / 1$ pepstatin. Protein concentrations were determined using the BCA protein assay kit (Pierce Biotechnology, Rockford, IL, USA). Samples were loaded onto a $10 \%$ SDS-polyacrylamide gel and transferred electrophoretically to nitrocellulose membranes (Pall, East Hill, NY, USA), analyzed with antibodies according to the manufacturer's instructions and visualized with peroxidase on an enhanced chemiluminescence system (ECL kit; Pierce Biotechnology). The following antibodies were used in the western blot analyses: anti-chymase, anti-TGF- $\beta 1$, anti-Smad 2 , anti-Smad3, anti-Smad7 and anti- $\beta$-actin (1:1,000 dilution; Santa Cruz Biotechnology, Santa Cruz, CA, USA).

Statistical analysis. All data are expressed as the means \pm SD. Comparisons of data among multiple treatment groups were evaluated by one-way analysis of variance (ANOVA) followed by post-hoc analysis (Fisher's test). p $<0.05$ was found to be statistically significant.

\section{Results}

PNFE attenuates heart remodeling. As shown in Table II, the cardiac hypertrophy indexes of human chymase transgenic mice were significantly higher than those of C57 BL/6 mice $(\mathrm{p}<0.05)$, whereas PNFE and SBTI treatment resulted in a significant reduction in LVHI, indicating beneficial effects of these two drugs on the cardiac hypertrophic state and an improvement in left ventricular remodeling in this transgenic animal model.

Expression of ventricular mRNAs encoding chymase, TGF- $\beta 1$, Smad2, Smad3 and Smad7. The RT-PCR analysis showed that expression of mRNAs encoding chymase, TGF- $\beta 1$, Smad 2 and Smad 3 mRNA in the transgenic mice was significantly higher than that of the C57 BL/6 mice. Treatment with PNFE effectively lowered the expression of ventricular mRNAs encoding chymase, TGF- $\beta 1$, Smad 2 and Smad3. SBTI, which was used as a positive control in our experiment, also exerted an attenuating effect similar to that of PNFE. On the other hand, Smad7 mRNA was found to be lower in transgenic mice than in C57 BL/6 mice, and treatment with PNFE significantly up-regulated its expression (Fig. 1).
Table II. Left ventricular hypertrophy indexes of all groups.

\begin{tabular}{lcccc}
\hline $\begin{array}{l}\text { Treatment } \\
\text { group }\end{array}$ & $\mathrm{n}$ & $\mathrm{VW}(\mathrm{mg})$ & $\mathrm{BW}(\mathrm{g})$ & $\begin{array}{c}\mathrm{VW} / \mathrm{BW} \\
(\mathrm{mg} / \mathrm{g})\end{array}$ \\
\hline Normal & 8 & $174.4 \pm 20.73$ & $29.14 \pm 1.57$ & $5.99 \pm 0.54$ \\
Control & 8 & $212.5 \pm 35.85^{\mathrm{a}}$ & $30.99 \pm 2.33$ & $6.83 \pm 0.83^{\mathrm{a}}$ \\
SBTI & 8 & $173.5 \pm 17.84^{\mathrm{b}}$ & $29.75 \pm 1.84$ & $5.83 \pm 0.41^{\mathrm{b}}$ \\
PNFE & 8 & $176.1 \pm 18.86^{\mathrm{b}}$ & $30.35 \pm 1.97$ & $5.80 \pm 0.76^{\mathrm{b}}$
\end{tabular}

All values present the means \pm SD. ${ }^{\mathrm{a}} \mathrm{p}<0.05$ compared to the normal group. ${ }^{b} \mathrm{p}<0.05$ compared to the control group. PNFE, Panax notoginseng flower extract; SBTI, soybean trypsin inhibitor; VW, ventricle weight; BW, body weight.

Protein expression of chymase, TGF- $\beta 1$, Smad2, Smad3 and Smad7. The protein expression levels of chymase, TGF- $\beta 1$, Smad2 and Smad3 were markedly up-regulated in the myocardium of human chymase transgenic mice, and the treatment with PNFE and SBTI significantly suppressed their expression. On the contrary, the protein expression of Smad7 was significantly lower than that in the control group. After treatment with PNFE and SBTI, the Smad7 protein levels were significantly elevated when compared to those of the control (Fig. 2).

\section{Discussion}

Panax notoginseng, known as San-qi in Chinese, is a wellknown and commonly used Chinese medicine. Due to its efficacy in promoting blood circulation, removing blood stasis, relieving swelling and alleviating pain, the root part of Panax notoginseng has been widely used to treat hemoptysis and hematomas in Chinese medical practice for centuries. More than $85 \%$ of Panax notoginseng comes from the Wenshan region in Yunnan Province, China (28). Phytochemical studies on the roots, leaves and flower buds of Panax notoginseng over the past several decades have led to the isolation and characterization of more than 50 dammaranetype saponins, which are believed to be the main bioactive components (29). Ginsenoside Rb3, one of the panoxadiols found in many Ginseng species, presents in a higher amount $(2.58 \%)$ in the flower buds of Panax notoginseng than in the root (30). However, since the most commonly used part of Panax notoginseng in herbal medicine is the root, the pharmacological effects of other parts, such as the flowers and leaves, have yet to be examined.

It has been reported that Panax notoginseng saponins have hemodynamic effects on anesthetized dogs (31). Recently, it was shown that Panax notoginseng flower extract possesses anticancer activity in vitro and in vivo (32-34), and protective effect on liver injury (35). The extract has also been shown to inhibit LPS-induced inflammatory response via the inhibition of the $\mathrm{NF}-\kappa \mathrm{B}$ signaling pathway in macrophages (36). Furthermore, it exhibited a neuroprotective effect on cultured neurons and the underlying action mechanism may involve anti-oxidative activity (37). By using AB-8 macroporous resin as the column packing material, we were able to separate and purify total saponins from Panax notoginseng flowers, and panoxadiol 
A

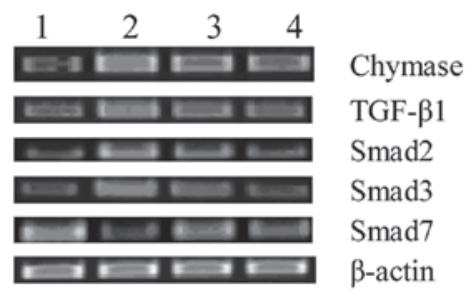

C

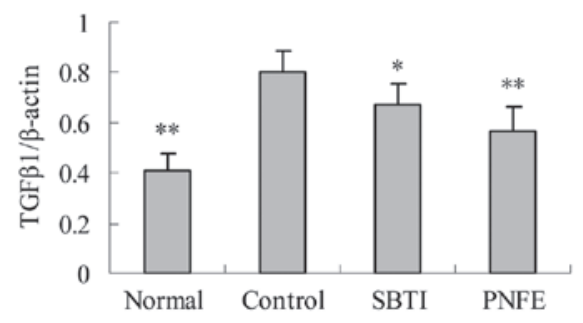

$\mathbf{E}$

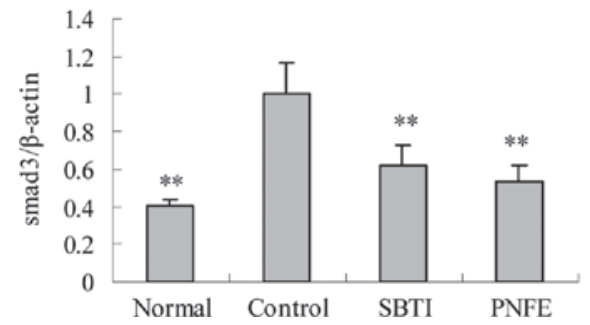

B

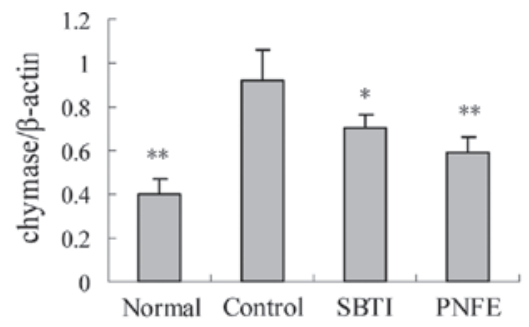

D

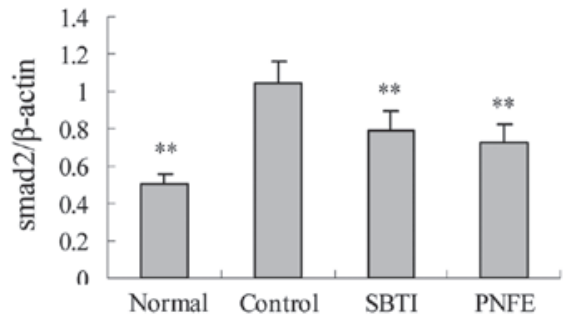

F

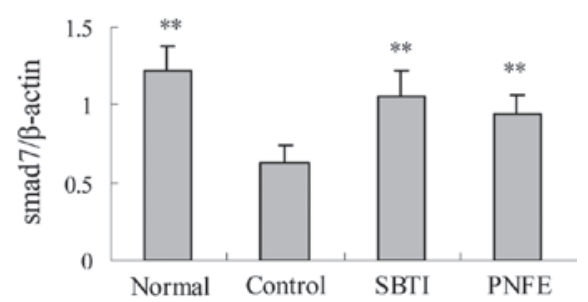

Figure 1. Effects of PNFE on the mRNA expression of chymase, TGF- $\beta 1$, Smad2, Smad3 and Smad7 in the myocardium of human chymase gene transgenic mice. (A) Representative examples of RT-PCR results (lane 1, normal; lane 2, control; lane 3, SBTI; lane 4, PNFE). Data are the means \pm SD (n=5). " $\mathrm{p}<0.05$; ${ }^{* *} \mathrm{p}<0.01$ compared to the control group.

A

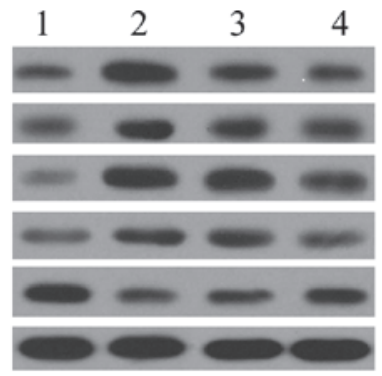

Chymase

TGF- $\beta 1$

Smad2

Smad3

Smad7

$\beta$-actin

C

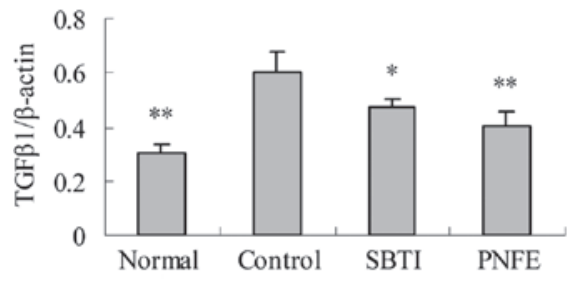

E

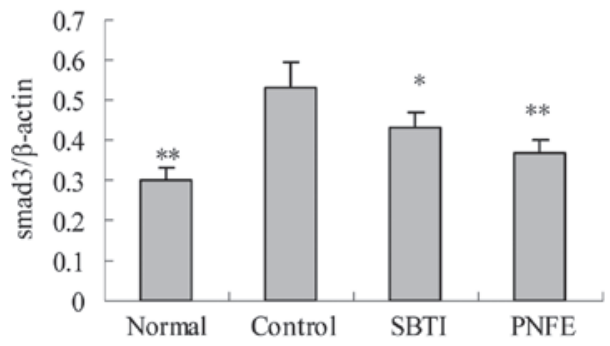

B

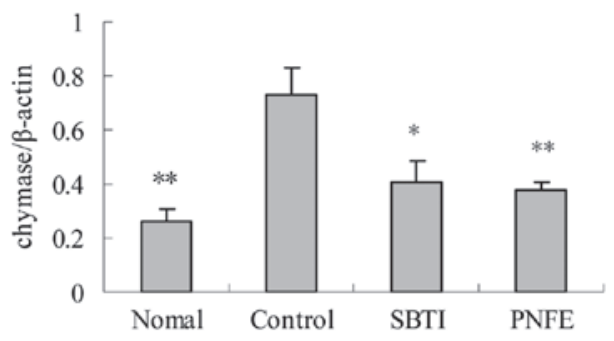

D

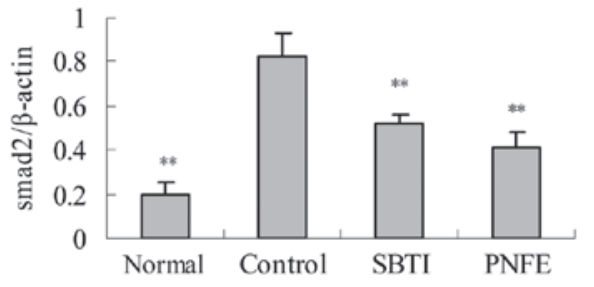

F

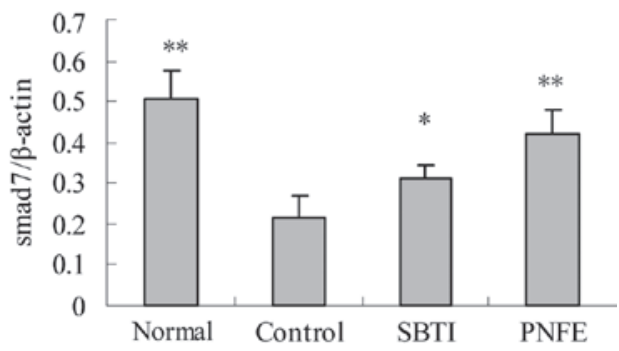

Figure 2. Effects of PNFE on the protein expression of chymase, TGF- $\beta 1$, Smad2, Smad3 and Smad7 in the myocardium of human chymase gene transgenic mice. (A) Representative Western blotting of protein expression. Bar chart presentation of the protein expression of (B) chymase, (C) TGF- $\beta 1$, (D) Smad2, (E) Smad3 and (F) Smad7. Data are the means $\pm \mathrm{SD}(\mathrm{n}=4)$. ${ }^{*} \mathrm{p}<0.05 ;{ }^{* *} \mathrm{p}<0.01$ compared to the control group. 
and notoginsenoside $\mathrm{Rb} 3$ were found to be the main saponin components in the extract. In this study, the total saponins in the dry PNFE was quantified to be $87.6 \%$, and the amount of ginsenoside Rb1 and Rb3 was 4.12 and $8.93 \%$, respectively.

Chymase, an alternative pathway for the generation of Ang II, exists in the heart, and has a higher specificity in humans for the conversion of Ang I to Ang II (5). Chymase plays an important role in heart remodeling by increasing Ang II formation, activating matrix metallopeptidase 9 (MMP-9), and regulating collagen I gene expression (8). Human chymase transgenic mice have widely been used as a hypertrophic cardiomyopathy model (38). In the present study, LVMI, chymase mRNA and protein levels in the myocardium of human chymase transgenic mice were significantly increased compared to those of C57 BL/6 mice. Moreover, TGF- $\beta 1$, Smad 2 and Smad 3 mRNA and protein levels in the myocardium of human chymase transgenic mice were markedly elevated, while Smad7 expression was reduced. The study also suggested that the expression of the human chymase gene in heart tissues of mice caused increased Ang II production and resulted in the hypertrophy of myocardiocytes, as well as an increase in the left ventricular anterior wall and posterior wall. In addition, it has been reported that chymase activates latent TGF- $\beta$ to form mature TGF- $\beta$, causing an increased collagen production $(39,40)$. Moreover, it has been shown that chymase inhibition suppresses TGF- $\beta 1$ transcription levels and prevents cardiac fibrosis in animal models $(9,18)$.

TGF- $\beta 1$ is the predominant TGF- $\beta$ isoform found in the heart, and through its signaling pathway TGF- $\beta 1$ activates effector proteins called Smads. The TGF- $\beta 1-$ Smad signaling pathway plays a crucial role in the development of cardiac remodeling (41). Smad2/Smad3 are key mediators of TGF- $\beta$ mediated activation according to the experimental findings of several in vitro and in vivo studies (42-45), while Smad6 and Smad7, the inhibitory Smads, are key regulators of TGF- $\beta$ signaling by negative feedback loops $(46,47)$.

Traditional Chinese medicine has long been used to treat many cardiovascular diseases, such as hypertension and coronary heart disease; however, the effect of Chinese herbal medicine on the TGF- $\beta 1 / \mathrm{Smad}$ signaling activation in hypertrophic remodeling in chymase transgenic animals has not been previously reported. In this study, we demonstrated for the first time that PNFE and SBTI, two proteinase inhibitors of tryptase and chymase $(9,14)$, significantly affected heart remodeling and altered the TGF- $\beta /$ Smad signaling transduction pathway in the myocardium of human chymase gene transgenic mice. PNFE treatment for 9 consecutive weeks was able to attenuate the LVMI, chymase mRNA and protein levels. In addition, PNFE treatment was capable of reducing TGF- $\beta 1$, Smad2, Smad3 mRNA and protein levels in the myocardium of human chymase transgenic mice. Treatment with PNFE and SBTI markedly accentuated the Smad7 mRNA and protein levels.

Taken together, our experimental results suggest that TGF- $\beta 1 /$ Smad signaling activation plays a critical role in the development of cardiac remodeling in human chymase transgenic mice. Treatment with PNFE effectively prevented heart remodeling in human chymase gene mice via modulating the expression of mRNA and protein of TGF- $\beta /$ Smads in the ventricular tissues. The experimental results help confirm a scientific foundation for the use of PNFE for treating cardiac hypertrophy in Chinese medical practice, and pave the way for further development of this natural product as an effective pharmaceutical agent for the treatment of this common debilitating cardiac condition.

\section{Acknowledgements}

The authors are grateful to Prof. Chen Lanying of the Cardiovascular Institute and $\mathrm{Fu}$ Wai Hospital, Chinese Academy of Medical Sciences and Peking Union Medical College, China and Sun Xiaojuan of the Institute of Laboratory Animal Science, Chinese Academy of Medical Sciences and Peking Union Medical College, China for constructing the human chymase gene transgenic mice. This study was supported in part by grants from the Special Foundation of State Ministry of Science and Technology, China (no. 2009GJC00001), the National TCM Trade Foundation of China (No.201007003-4), and from the High and New Technology Industry Foundation of Shanghai, China (no. XIAO-151- FANGXIANG-22b).

\section{References}

1. Swynghedauw B: Molecular mechanisms of myocardial remodeling. Physiol Rev 79: 215-262, 1999.

2. Kato N, Hyne G, Bihoreau MT, Gauguier D, Lathrop GM and Rapp JP: Complete genome searches for quantitative trait loci controlling blood pressure and related traits in four segregating populations derived from Dahl hypertensive rats. Mamm Genome 10: 259-265, 1999.

3. Pravenec M, Zidek V, Musilova A, Vorlicek J, Kren V, St Lezin E and Kurtz TW: Genetic isolation of a blood pressure quantitative trait locus on chromosome 2 in the spontaneously hypertensive rat. J Hypertens 19: 1061-1064, 2001.

4. Arnett DK, de las Fuentes L and Broeckel U: Genes for left ventricular hypertrophy. Curr Hypertens Rep 6: 36-41, 2004.

5. Urata H, Kinoshita A, Misono KS, Bumpus FM and Husain A: Identification of a highly specific chymase as the major angiotensin II-forming enzyme in the human heart. J Biol Chem 265: 22348-22357, 1990.

6. Petella V, Marinò I, Arbustini E, Lamparter-Schummert B, Verga L, Adt M and Marone G: Stem cell factor in mast cells and increased mast cell density in idiopathic and ischemic cardiomyopathy. Circulation 97: 971-978, 1998.

7. Miyazaki M, Takai S, Jin D and Muramatsu M: Pathological roles of angiotensin II produced by mast cell chymase and effects of chymase inhibition in animal models. Pharmacol Ther 112: 668-676, 2006.

8. Chen LY, Li P, He Q, Jiang LQ, Cui CJ, Xu L and Liu LS: Transgenic study of the function of chymase in heart remodeling. J Hypertens 20: 2047-2055, 2002.

9. Matsumoto T, Wada A, Tsutamoto T, Ohnishi M, Isono T and Kinoshita M: Chymase inhibition prevents cardiac fibrosis and improves diastolic dysfunction in the progression of heart failure. Circulation 107: 2555-2558, 2003.

10. Kanemitsu H, Takai S, Tsuneyoshi H, Nishina T, Yoshikawa K, Miyazaki M, Ikeda T and Komeda M: Chymase inhibition prevents cardiac fibrosis and dysfunction after myocardial infarction in rats. Hypertens Res 29: 57-64, 2006.

11. Palaniyandi SS, Nagai Y, Watanabe K, Ma M, Veeraveedu PT, Prakash P, Kamal FA, Abe Y, Yamaguchi K, Tachikawa H, Kodama M and Aizawa Y: Chymase inhibition reduces the progression to heart failure after autoimmune myocarditis in rats. Exp Biol Med 232: 1213-1221, 2007.

12. Matsumoto C, Hayashi T, Kitada K and Yamashita C: Chymase plays an important role in left ventricular remodeling induced by intermittent hypoxia in mice. Hypertension 54: 164-171, 2009.

13. Borland JA, Chester AH, Morrison KA and Yacoub MH: Alternative pathways of angiotensin II production in the human saphenous vein. Br J Pharmacol 125: 423-428, 1998.

14. He SH, Chen HQ and Zheng J: Inhibition of tryptase and chymase induced nucleated cell infiltration by proteinase inhibitors. Acta Pharmacol Sin 25: 1677-1684, 2004. 
15. Lijnen PJ, Petrov VV and Fagard RH: Induction of cardiac fibrosis by transforming growth factor- $\beta 1$. Mol Genet Metab 71: 418-435, 2000.

16. Takai S, Jin D, Sakaguchi M, Katayama S, Muramatsu M, Sakaguchi M, Matsumura E, Kim S and Miyazaki M A novel chymase inhibitor, 4-[1-\{[bis-(4-methyl-phenyl)-

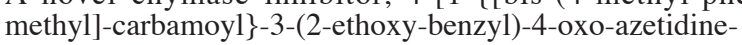
2-yloxy]-benzoic acid (BCEAB), suppressed cardiac fibrosis in cardiomyopathic hamsters. J Pharmacol Exp Ther 305: 17-23, 2003.

17. Takai S, Jin D and Miyazaki M: Targets of chymase inhibitors. Expert Opin Ther Targets 15: 519-527, 2011.

18. Kanemitsu H, Takai S, Tsuneyoshi H, Yoshikawa E, Nishina T, Miyazaki M, Ikeda T and Komeda M: Chronic chymase inhibition preserves cardiac function after left ventricular repair in rats. Eur J Cardiothorac Surg 33: 25-31, 2008.

19. Zhao XY, Zhao LY, Zheng QS, Su JL, Guan H, Shang FJ, Niu XL, He YP and Lu XL: Chymase induces profibrotic response via transforming growth factor-beta $1 /$ Smad activation in rat cardiac fibroblasts. Mol Cell Biochem 310: 159-166, 2008.

20. Yoshikawa M: Physiological functions of Panax notoginseng. Shokuhin to Kagaku 44: 35-38, 2002.

21. Dan B, Steven C and Erich S: Chinese Herbal Medicine: Materia Medica. Vol. 3. Eastland Press, Seattle, 2004

22. Huang YS, Yang ZC, Yan BG, Hu XC, Li AN and Crowther RS: Improvement of early postburn cardiac function by use of Panax notoginseng and immediate total eschar excision in one operation. Burns 25: 35-41, 1999.

23. Cicero AFG, Bandieri E and Arletti R: Orally administered Panax notoginseng influence on rat spontaneous behaviour. J Ethnopharmacol 73: 387-391, 2000.

24. Xuejiang W, Ichikawa $\mathrm{H}$ and Konishi T: Antioxidant potential of qizhutang, a Chinese herbal medicine, and the effect on cerebral oxidative damage after ischemia reperfusion in rats. Biol Pharm Bull 24: 558-563, 2001.

25. Liu S and Chen JX: Anti-arrhythmic effect of total saponins of Panax notoginseng. Zhongguo Yao Li Xue Bao 5: 100-103, 1984

26. $\mathrm{Li} \mathrm{W}$ and Hao Z: Studies on separation and purification of total saponin from flower buds of Panax notoginseng by Macroporous resins. J Chinese Med Mater 31: 1418-1421, 2008.

27. He Q, Chen LY, Dai YP, Chen YF and Liu LS: The cloning of MLC2-chymase fusion gene and the production of transgenic mice. Chinese J Biochem Mol Biol 4: 144-149, 1998.

28. Wei JX and Du YC: Modern Science Research and Application of Panax notoginseng. Yunnan Science and Technology Press, Kunming, China, 1996.

29. Wang CZ, McEntee E, Wicks S, Wu JA and Yuan CS Phytochemical and analytical studies of Panax notoginseng (Burk.) FH Chen. J Nat Med 60: 97-106, 2006.

30. Gao X, Dan M, Zhao A, Xie G and Jia W: Simultaneous determination of saponins in flower buds of Panax notoginseng using high performance liquid chromatography. Biomed Chromatogr 22: 244-249, 2008.

31. Chen ZH, Wang DC, Li HL, Wei JX, Wang JF and Du YC: Hemodynamic effects of san chi (Panax notoginseng) root, leaf, flower and saponins on anesthetized dogs. Yao Xue Xue Bao 18: 818-822, 1983

32. Wang CZ, Luo X, Zhang B, Song WX, Ni M, Mehendale S, Xie JT, Aung HH, He TC and Yuan CS: Notoginseng enhances anticancer effect of 5-fluorouracil on human colorectal cancer cells. Cancer Chemother Pharmacol 60: 69-79, 2007.
33. Wang CZ, Xie JT, Fishbein A, Aung $\mathrm{HH}$ and $\mathrm{He} \mathrm{H}$ : Antiproliferative effects of different plant parts of Panax notoginseng on SW480 human colorectal cancer cells. Phytother Res 23: 6-13, 2009.

34. Ke Y, Jiang JY, Wang XZ, Zeng XY and Zhu CY: Effect of total saponins from rhizomes and flowers of Panax notoginseng on tumor cell induced platelet aggregation. Zhong Yao Cai 33: 96-99, 2010.

35. Yoshikawa M, Morikawa T, Kashima Y, Ninomiya K and Matsuda H: Structures of new dammarane-type triterpene saponins from the flower buds of Panax notoginseng and hepatoprotective effects of principal ginseng saponins. J Nat Prod 66: 922-927, 2003

36. Jung HW, Seo UK, Kim JH,Leem KH and Park YK: Flower extract of Panax notoginseng attenuates lipopolysaccharide-induced inflammatory response via blocking of NF-kappaB signaling pathway in murine macrophages. J Ethnopharmacol 122: 313-319, 2009.

37. Choi RC, Jiang Z, Xie HQ, Cheung AW, Lau DT, Fu Q, Dong TT, Chen J, Wang $\mathrm{Z}$ and Tsim KW: Anti-oxidative effects of the biennial flower of Panax notoginseng against $\mathrm{H}_{2} \mathrm{O}_{2}$-induced cytotoxicity in cultured PC12 cells. Chin Med 5: 38-44, 2010.

38. Dong W, Quan XZ, Song MJ, Feng J and Zhang LF: Analysis of the heart function of human chymase gene transgenic mice with echocardiography. Chin J Compara Med 17: 633-636, 2007.

39. Kofford MW, Schwartz LB, Schechter NM, Yager DR, Diegelmann RF and Graham MF: Cleavage of type I procollagen by human mast cell chymase initiates collagen fibril formation and generates a unique carboxyl-terminal propeptide. J Biol Chem 272: 7127-7131, 1997.

40. Lindstedt KA, Wang Y, Shiota N, Saarinen J, Hyytiainen M, Kokkonen JO, Keski-Oja J and Kovanen PT: Activation of paracrine TGF-betal signaling upon stimulation and degranulation of rat serosal mast cells: a novel function for chymase. FASEB J 15: 1377-1388, 2001.

41. Chuva de Sousa Lopes SM, Feijen A, Korving J, et al: Connective tissue growth factor expression and Smad signaling during mice heart development and myocardial infarction. Dev Dyn 231: 542-550, 2004

42. Schifferl M, von Gersdorff G, Bitzer M, Susztak K and Böttinger PE: Smad proteins and transforming growth factor- $\beta$ signaling. Kidney Int (Suppl 77): 45-52, 2000.

43. Ten Dijke P and Hill CS: New insights into TGF-beta-Smad signalling. Trends Biochem Sci 29: 265-273, 2004.

44. Phanish MK, Wahab NA, Colville-Nash P, Hendry BM and Dockrell ME: The differential role of Smad2 and Smad3 in the regulation of pro-fibrotic TGF $\beta 1$ responses in human proximaltubule epithelial cells. Biochem J 393: 601-607, 2006.

45. Bujak M and Frangogiannis NG: The role of TGF- $\beta$ signaling in myocardial infarction and cardiac remodeling. Cardiovasc Res 74: 184-195, 2007.

46. Bujak M, Ren G, Kweon HJ, Dobaczewski M, Reddy A, Taffet G, Wang XF and Frangogiannis NG: Essential role of Smad3 in infarct healing and in the pathogenesis of cardiac remodeling. Circulation 116: 2127-2138, 2007.

47. Wang B, Hao J, Jones SC, Yee MS, Roth JC and Dixon IMC: Decreased Smad 7 expression contributes to cardiac fibrosis in the infracted rat heart. Am J Physiol Heart Circ Physiol 282: H1685-H1696, 2002. 